DOI: http://dx.doi.org/10.22483/2177-5796.2017v19n3p579-590

\title{
Andanças e desassossegos em cartas que não exigem respostas
}

\author{
Leandro Belinaso Guimarães
}

Resumo: O ensaio reúne três cartas escritas entre março e abril de 2017. Foram endereçadas, inicialmente, a estudantes de um curso de Licenciatura, mas escritas para serem lidas por qualquer pessoa. A questão multicultural emerge nelas a partir da coleta de diferentes repertórios que as andanças pelas cidades e os encontros cotidianos propiciaram. A série ensaística de cartas esforça-se por mostrar o que se potencializa na entrega do corpo e do pensamento aos encontros com uma cidade, um amigo, um professor, uma estudante, uma fotografia, uma narrativa, um filme, um romance, um museu, uma ventania, uma chuva, um copo de água, um gesto, um ruído, um instante.

Palavras-chave: Arte. Cotidiano. Formação. Narrativa.

\section{Wandering and unrest in letters that do not require an answer}

\begin{abstract}
This essay brings together three letters written between March and April of 2017. They were addressed to undergraduate students, but they could be read by anyone. A multicultural issue emerges in them from the collection of different repertoires that come about from wandering around cities and from everyday meetings. The essay-esque series of letters endeavours to demonstrate the potential of giving oneself, their body and thought to encounters with a city, a friend, a teacher, a student, a photograph, a narrative, a movie, a novel, a museum, or even the wind, the rain, a glass of water, a gesture, a sound or an instant.
\end{abstract}

Keywords: Art. Everyday. Education. Narrative. 


\section{$1 \mathrm{Um}$ começo...}

Queridos/as estudantes,

Foi com muita alegria que estive com vocês pela primeira vez. A sexta começou desejosa do aroma do café recém-passado. Para o Dinkel (meu gato), o dia inicia quando o sol ainda espreguiça, abrindo lentamente um olho. Junto, os pássaros festejam o abandono da noite. Sinal que para o Dinkel significa: "pessoal venham assistir o dia chegar com a gente". "Antes, que tal me dar comida?" Tudo bem, mas gostaria de ter a chance de me espreguiçar como o sol e ser menos alegre que os pássaros, ao mesmo nessa hora da madrugada.

Guardei para a sexta, que teria meu primeiro encontro com vocês do PIBID (Programa Institucional de Bolsas de Iniciação à Docência), algo muito importante. Espera um pouquinho que já conto. Antes, alguns pensamentos que passaram pela minha cabeça quando estava a caminho da Universidade Federal de Santa Catarina: "Eles devem se conhecer muito bem. Estar há anos trocando experiências. Tenho que chegar com calma. Haverá uma outra relação começando, já que cada um é um mundo feito de muitos outros. Calma. Deixa acontecer. Respira”. E cheguei ofegante, suado, morrendo de calor. Quando sentei, a primeira coisa que vi foi a mesa.

Se colocássemos um objeto bem no meio dela, só subindo em cima para conseguir pegar. Não há braço que possa fazer isso sozinho. Como pode uma mesa majestosa querer todo o espaço só para ela, enquanto vinte e três corpos humanos se achatam contra a parede. Achei a mesa um pouco metida, com um ar de soberana.

Quando olhei o pessoal que já estava por lá e outros que foram chegando depois de mim, pensei: onde eu estive esses anos todos para conhecer tão pouca gente? Quase ninguém foi meu aluno ou minha aluna, como pode? Claro, em 2013 fiz um pós-doutorado e passei parte daquele ano como pesquisador visitante na Universidade de Amsterdã e, quando retornei, fui trabalhar na Pedagogia com a disciplina "Ciência, Infância e Ensino". Baguncei muito essa disciplina por lá. Foi incrível, ao menos para mim. Mas acho que algumas alunas gostaram também. Todas as aulas foram ministradas em forma de oficina. Ficava exausto, mas valia a pena. Um dia, em 2015, um grupo de alunas do curso noturno da Licenciatura em Ciências Biológicas (não eram muitas, acho que três, mas para mim mais que um já é multidão) foram até a minha sala de aula na Pedagogia dizer que queriam cursar comigo o "Estágio Supervisionado no ensino de ciências". Perguntaram 
se eu não voltaria mais. Fiquei emocionado com o convite. Pensei. Pensei. Pensei e resolvi ministrar novamente o Estágio para a turma do noturno. Em 2016, voltar ao curso de Biologia me fez sentir um professor iniciante. Quando vi já tinha criado novas bagunças com clubes de escrita, parques urbanos de proteção ambiental, cineclube, turmas de Educação de Jovens e Adultos (EJA), salas de aula de ciências, articulando tudo isso aos estágios. Está sendo bom voltar e agora ficar próximo de vocês do PIBID é um novo desafio.

Vejam que sem planejar estou escrevendo uma carta - foi neste momento que dei um título a esta narrativa. Logo conto o que prometi no começo. Algo importante que guardei para este primeiro dia de PIBID. Que delícia são as cartas, vocês não acham? Lembro das longas trocadas com uma namorada que conheci em uma viagem à São Paulo (não tinha Internet na época, podem acreditar?). Cartas viajantes, acompanhadas de fitas K7 (cabiam umas 20 músicas, acho, o que me exigia um esforço enorme de seleção) para a sonorização imprescindível à leitura. Lembro também das palavras mínimas enviadas pelo correio ao meu pai (que acaba de fazer oitenta e um anos), durante o tempo em que ele teimou em ficar sem telefone.

Há dois anos li uma carta não endereçada a mim. Não sei bem o motivo, mas ela mexeu muito comigo. Trata-se do livro "Caderno de um ausente”, de João Anzanello Carrascoza (2017), o primeiro volume de sua "Trilogia do Adeus". Vocês conhecem? É uma carta remetida por um pai à sua filha recém-nascida. Ele, com idade de avô, escreve sobre o futuro, sobre o tempo em que estará ausente do mundo. É muito intenso e tocante. Mas ele não fala tudo, pois afirma, lá pelas tantas, que há coisas que não devemos saber para que possam doer menos. Das muitas passagens que grifei do livro, há uma que quero dar de presente a vocês: "a vida é o resumo de algo que não podemos alcançar”. Não sei bem o porquê, mas acho que essa frase diz muito do belíssimo filme "Manchester à beira mar". Se não viram, sugiro muito, mas alerto: é triste, bem triste, triste mesmo. Mas é possível sorrir em alguns momentos ao longo da projeção.

Chega de digressão e vamos ao que desejo contar desde o inicio para vocês. Desde quando sentei e comecei a escrever e, de repente, passei a falar sobre um monte de outras coisas não planejadas. Elas simplesmente saíram.

Nos últimos anos orientei uma dissertação de mestrado, da Sheila Hempkemeyer (2016), sobre como as pessoas se formam, se educam, na relação com a bicicleta e a cidade. A pergunta que movimentou a pesquisa foi: “por onde pedalam seus desejos”? É sempre importante, em uma prática pedagógica, que possamos brincar, inventar, criar, tecer, perguntas potentes, para que elas 
possam abrir mundos impensáveis em nós. Aliás, que perguntas vocês têm movimentado nas escolas em que atuam? Estou muito curioso para saber. Quais seriam as perguntas que solicitam novas indagações e suspendem as respostas, as certezas, as verdades?

A bicicleta, como diz Marc Auge (2015), é um pequeno objeto incorporado, não um espaço habitado como o automóvel. Como defendeu Sheila em sua dissertação, humano e bicicleta se amalgamam em um corpo híbrido. Não habitamos uma bicicleta, somos outros com ela, uma corporeidade outra. E não é que passei a usar (que verbo ruim, tenho que trocar por outro depois) a bicicleta para alguns deslocamentos cotidianos? Estou tão feliz com isso que vocês não imaginam. Ainda não tinha ido à UFSC com a easy rider. Deixei para inaugurar esse trajeto no primeiro encontro do PIBID. Com isso eu o tornaria marcante em minha vida. Algo a ser sempre rememorado. Isso explica porque cheguei esbaforido no encontro. É que estava envolto em uma espécie de devir-criança. As crianças nos ensinam a inventar ficções no cotidiano de nossas existências. Acho que deveríamos escutá-las mais, não acham?

Um forte abraço,

Leandro Belinaso Guimarães Ilha de Santa Catarina, 11 de março de 2017 (manhã de sábado)

\section{Desassossegos}

Querida Isadora,

Espero que esta carta lhe encontre desassossegada. Pode parecer estranho desejar isso a alguém. É que ando lendo muita poesia ultimamente, sobretudo, a de Manoel de Barros. E seus versos nos tiram daquele estado torpe, rasteiro, medíocre que algumas vezes inunda nossa existência cotidiana. Estar em desassossego nos permite, quem sabe, encontrar uma saída potente para tudo aquilo que insiste em se impor tristemente a nós. Precisamos fugir, Isa, das linhas tranquilizadoras, endurecidas, burocráticas e poderosas instaladas em gabinetes higienizados e apartados das gambiarras do mundo. Estar na rua, tecer-se nos encontros cotidianos, entregar-se aos experimentos criadores de vidas variadas e abertas à alteridade. Acredito que estar em desassossego é simplesmente viver intensamente a vida, a formação, os processos educativos. 
E como, Isadora, levar esse desassossego à educação? Como? Como "remontar" a formação, sempre, porque não queremos "mais viver em desamor", como nos diz a cantora Liniker. O poeta Waly Salomão (2014) nos alerta que a vida (e eu diria a educação, o ensino, a formação) pode ser remontada, reeditada, remasterizada, tal como o "amor pixelado" cantado no CD “Tropix” pela Céu. E como poderíamos remixar nossas aulas escolares de biologia e cultura e arte (ao menos na escola elas podem estar juntas, você não acha?), em um movimento insistente de criação de um novo ainda não presente em nós, nem no mundo que vemos e lemos?

Entendo a arte na educação, Isa, um pouco como a pesquisadora em educação Luciana Loponte (2016). A arte como uma plataforma para pensar. Como podemos nos inserir poética e artisticamente no mundo? Os artefatos e processos provenientes disso que chamamos arte não estão ai para nós - sujeitos envolvidos com o ensino - interpretarmos, compreendermos racionalmente. Acho que não. Muito menos para com a arte tornarmos mais interessante e palatável um assunto da biologia, da ciência, em sala de aula. A arte, diria Luciana, é para nos inspirar a inventar outros modos de viver e pensar. Desse modo, como fazer uma aula escolar de biologia se encontrar com a arte e a cultura? Pode a docência ser pensada como um ato de criação?

Quantas perguntas. Desculpe Isadora. Acho que me passei um pouco. Fale-me de você. Como você tem andado lá pelas bandas do PIBID? Ouvi dizer que o PIBID é um "lote vago", como diria Breno Silva e Louise Ganz (2009), um campo aberto a ser pensado e criado. Se for isso mesmo, quantas possibilidades se abrem. Conte-me mais. Você já acampou por lá? O terreno do PIBID já foi capinado? Precisa de adubo? Tenho um pouco de húmus aqui em casa. Posso levar para você. Tenho também uma enxada para emprestar, mas está um pouco gasta. Você tem uma enxada? Sugiro comprar. Vale muito o investimento. Ou adotar uma. Há muitas abandonadas. A minha sempre foi uma grande companheira. Minha enxada sempre me escutou quando precisei desabafar. Nunca reclamou de estar em contato comigo, com a terra, o chão, o sol, a chuva, a rua. É bom estar próximo de uma enxada Isadora. Quando estamos pelo mundo sedentos por criar algo que nos faça esquecer de nossos egos, uma enxada é sempre uma ótima companhia. Ela ajuda a gente a revirar um pouco o terreno, mover a terra, criar sulcos, plantar, replantar. Foi a Ana Godoy quem me deu esse toque.

Isadora, me diz uma coisa. Você já tirou fotos da escola? Já escreveu sobre seu deslocamento até ela? Queria tanto ler você. Compartilha comigo. Se desejar, claro. Fiquei tão 
empolgado com as fotografias da Raquel e da Juliana tiradas no Instituto Estadual de Educação. Você gostou? E a conversa sobre as sonoridades das imagens e sobre como as dotar de cor. Que bate-papo saboroso. Quanta potência para levarmos às crianças e aos jovens e nos deixarmos contaminar com suas alegrias.

E os encontros lá na Escola Estadual Getúlio Vargas? Nossa, para mim foi ótimo retornar ao colégio depois de alguns anos. Ver a escola com certa lentidão, mediado pela presença sua e dos outros bolsistas. Achei incrível aquele vasto muro no fundo, gritando por cor. Lembro até de uma árvore querendo entrar na escola, tentando dia a dia remover o pedaço de parede que a impede de estar ali com as crianças. Nossa, minha enxada adoraria aquele pátio imenso nos pedindo para ser remexido, revirado, repensado, repisado. E o pau-brasil ainda sem nome na entrada da escola, que histórias ele já viveu por lá? Sabe de alguma?

Eu falei antes que iria parar com as perguntas e não consegui. Você pode me responder o que quiser, ou coisa nenhuma. Fico aguardando alguma notícia, mesmo que breve. Se souber de alguma enxada disponível à adoção eu te digo. Agora vou indo que ainda quero estudar uma música do Radiohead, para tentar tocá-la no meu violão. Ele não é feito de pau-brasil, nem veio da China. É o irmão mais novo da enxada. Sempre se deram super bem, embora sejam tão diferentes. Um gosta do frio e o outro do calor. Um ama a noite e o outro o dia. Adotei os dois ao mesmo tempo. Não quis separar irmãos. Acho que foi a melhor coisa que já fiz na vida.

Beijos e abraços,

Leandro Belinaso Guimarães

Ilha de Santa Catarina, 22 de abril de 2017

(manhã de sábado)

\section{Andanças}

A todos que leram as cartas anteriores ou nenhuma,

Alguns de vocês sabem, outros não. A partir de março deste ano de 2017 passei a ir mensalmente a São Paulo para os encontros do Laboratório do Sensível, coordenado pelo professor e escritor João Anzanello Carrascoza. Fico sempre hospedado na Vila Clementino, um pedaço da Vila Mariana, na casa de um casal de amigos. Ela está a alguns passos do Parque Ibirapuera. $\mathrm{Na}$ ida do mês de abril corri lá uns $10 \mathrm{~km}$ com o Alexandre. Estava uma noite muito 
agradável de terça-feira e nos empolgamos jogando conversa fora no compasso da respiração apressada, mas ritmada e tranquila. Somos amigos há quase quarenta anos. Quanto tempo pode durar uma amizade? Além de ser próximo ao parque, o apartamento fica coladinho à Cinemateca e ao Museu de Arte Contemporânea. Localização maravilhosa. Vou caminhando até o local dos encontros mensais das terças à tarde, na Escola Superior de Propaganda e Marketing (ESPM).

$\mathrm{Na}$ primeira vez, em março, confesso que estava um pouco apreensivo. Afinal sou um grande apreciador dos livros do Carrascoza. Estar com ele em uma Universidade famosa e ao mesmo tempo enigmática para mim, conhecer seus orientandos, saber das pesquisas e dos detalhes dos novos desafios que se iniciariam; tudo isso gerou ansiedade em mim. Cheguei tão cedo que pude esperar quase uma hora em um café nas redondezas, antes de me dirigir à sala 030030-C da ESPM. Iniciei minha participação já pensando e rascunhando um ensaio sobre a poética de Manoel de Barros, para integrar uma publicação que o Laboratório está preparando para rememorar os 100 anos do nascimento do poeta. Passei parte considerável de março e de abril lendo sua poesia pantaneira e universal, um pouco da fortuna crítica escrita sobre ela e de textos os mais diversos que considerei interessantes para aquilo que começava a desejar escrever. Mas não é exatamente sobre isso que quero contar agora para vocês. Quero falar dessas minhas andanças por São Paulo. O começo delas.

Na ida de março fui de metrô na segunda-feira anterior à reunião, no dia da chegada à São Paulo, até a Pinacoteca visitar seu acervo. E tive uma surpresa. Fui capturado por obras contemporâneas expostas nas salas dedicadas a pinturas de outros séculos. Os textos que as acompanhavam continham uma proposição para o público. Perguntas que nos indicavam uma possibilidade de leitura. Eram abertas o suficiente para que embarcássemos em outras histórias que não as que pediam, delicadamente, que construíssemos. Fiquei fascinado com a imagem "Menina em Verde", de Luiz Braga. Um estranhamento provocado pela cor, pela pele. Fiquei muito tempo ou um tempo considerável, não sei, diante desta fotografia. Esqueci completamente de estabelecer uma conversa dela com as pinturas retratistas do século XIX expostas na mesma sala, tal como nos pedia o texto que acompanhava a fotografia. Fiquei nela, capturado por sua luz.

Outra imagem que surtiu um efeito hipnótico em mim, embora muito menor, menos impactante que a de Luiz Braga foi a do "Largo da Concórdia", de Tuca Vieira. Ela nos apresenta um ponto de vista inusitado, porque aéreo, suficientemente distante da nossa possibilidade mais 
corriqueira de ver, já que estamos, com nossos corpos transeuntes, comumente presos ao chão do largo. Mas a visão proposta pela fotografia não é panorâmica, não deixa ver horizontes. Ela é tão fragmentada quanto a nossa de transeuntes. Foi isso que achei incrível nela.

Lembrei agora, neste momento de escrita da carta, que fui na Pinacoteca para ver as fotografias de Candida Höfer, sobre as quais havia lido no jornal "O Estado de S. Paulo". Imagens silenciosas e simétricas de lugares grandiosos, repletos de coisas e, ao mesmo tempo, nos dando uma sensação de vazio. Como a que por vezes tenho quando visito bibliotecas públicas. As imagens, quando sobre elas li no jornal impresso, me preencheram de curiosidade. Eram bem poucas fotografias que estavam sendo exibidas, mas já foram suficientes para me fazer pensar sobre o silêncio das coisas que convivem conosco. De como somos nós, em nossa demasiada humanidade, que as calamos.

$\mathrm{Na}$ viagem de abril me deixei levar pelo que a cidade me ofertava. Tracei um mapa, mas me desviei dele algumas vezes. Comecei aquela manhã de quarta-feira, no dia seguinte ao encontro na ESPM, no SESC Ipiranga, visitando a exposição "Contaminações”. Foi avassalador. Carreguei comigo o segundo romance da "Trilogia do Adeus" do Carrascoza ("Menina escrevendo com pai”). Uma carta narrada por uma filha. Já havia lido "Caderno de um ausente”, o primeiro volume, a dilacerante carta escrita pelo pai à filha que viverá, um dia, a ausência dele. Me propus um desafio: ler o livro ao longo do dia, no decorrer das minhas andanças por São Paulo. Já o iniciei na noite anterior. Dormi quando as palavras começaram a embaralhar e precisava voltar ao começo do parágrafo mais de uma vez.

"Contaminações" promoveu o encontro entre obras literárias e visuais, provocou penetrabilidades entre elas. Algo que me esforço em praticar nos meus trabalhos com a formação docente. Coletar repertórios de vários lugares (cada vez mais da literatura), de diferentes linguagens e tentar contaminar com elas as oficinas e as aulas. Estou convencido de que ler textos acadêmicos provenientes daquilo que chamamos "área de pesquisa" já não é mais suficiente, embora seja necessário para que saibamos o que combater. O pensamento e o corpo sempre podem mais. Contaminar para variá-los e para romper com o que se espera deles. E a arte ajuda muito neste processo formativo e rebelde.

Uma das obras literárias visualmente exposta no SESC foi "Eles eram muito cavalos". Livro de Luiz Ruffato, que li por indicação de Marcos Reigota, costurado por histórias fragmentadas de inúmeras personagens ficcionais invisíveis da cidade de São Paulo. Na 
exposição nos encontramos com as personagens. Com suas silhuetas, seus rostos, seus corpos grafados em espécies de totens de madeira. Foi emocionante o que nos permitiu viver o artista Cristiano Mascaro. E junto a elas nos deparamos com a obra do artista amazonense Roberto Evangelista, chamada "Ritos de Passagem", que fora exposta anos atrás em uma Bienal de Artes na cidade e que inspirou o escritor a arquitetar o romance. Estou aqui escrevendo a vocês com o material educativo da exposição em mãos. Nele leio alguns escritos que parecem ser do próprio escritor ou, então, dos curadores, isso não fica claro, mas gostaria de compartilhar:

o tempo agora não é paulatino e sequencial, mas sucessivo e simultâneo. Assumir a fragmentação como técnica [...] e a precariedade como sintoma. [...] Construir subjetividades em um mundo que nos quer homogeneamente anônimos. Não a composição, mas a decomposição.

Ali no SESC Ipiranga, no meio da manhã, começou a chover. Sentei em um banco protegido pela larga marquise, de frente à parte externa do convidativo prédio. Avistava de longe as personagens do livro. Naquele momento escrevi o que passo a mostrar logo abaixo. Um texto curto escrito à mão em meu caderno vermelho (talvez seja alaranjado ou da cor de uma goiaba madura) que me acompanha desde o início do ano. Escrevi e fiquei, ali, lendo o livro do Carrascoza por um bom tempo.

Acabo de encontrar as personagens de "Eles eram muito cavalos". Estão todas aqui, na minha frente, em pé, caladas em seus gestos miúdos, cotidianos, únicos. Nosso encontro silencioso está durando um tempo inapreensível. Breve, mas volumoso. Não é todo dia que esbarramos com as personagens que lemos em romances e livros de contos. Sinto que estão desamparadas. Algumas não conseguem se proteger da chuva. Fora das palavras, das páginas que as abrigam, que as iniciam, ficam à deriva, entregues ao clima instável do mundo, sujeitas a fazer parte de outras histórias. Já não são mais as personagens de um livro. Agora estão também aqui, na minha outra leitura, no meu caderno, na minha história. Nas palavras que já não são mais minhas. São de quem as lê.

A partir do SESC circulei um pouco pela bonita e arborizada região. Visitei o Parque da Independência (anos atrás vi ali com o Jorge um show gratuito da Norah Jones) e a parte externa do Museu do Ipiranga. Tudo embaixo de uma garoa que logo virou chuva torrencial. Mas deu tempo até de tomar uma água de coco, sentir o vento se intensificar e encontrar, já bastante molhado, um lugar para comer. Depois de almoçar parti para o Instituto Tomie Ohtake. Fui conferir a exposição "O céu ainda é azul, você sabe...". Uma retrospectiva das obras da artista visual Yoko Ono.

No saguão de entrada da exposição nos deparamos com obras de outros artistas que haviam sido provocados por Yoko Ono. Quando me dei por conta já estava há quase uma hora 
ali, sem ver obras assinadas pela própria artista. Ou aquele conjunto já seria também dela? Percebi que suas instalações só aconteciam como "objetos expositivos" quando construídos ativamente pelo público, seja ele composto por artistas ou não. Sem o outro a exposição não existiria, literalmente. E foi isso que permitiu o "evento água" estar na mostra, ocupar um lugar no museu. Artistas foram convidados por Yoko Ono a criar recipientes de água para recolhê-la e ofertá-la a pessoas específicas ou à própria terra, que, como diz a artista, "desesperadamente" precisa dela. Incrível a força das narrativas que acompanhavam os recipientes criados, indicando a quem a água estaria endereçada. Diante delas só pude silenciar.

Várias instalações me capturaram imensamente. A artista convidou pela internet, por exemplo, mulheres a fotografarem seus olhos e enviarem juntamente com a imagem narrativas sobre as violências física ou simbólica que teriam sofrido. Passei muito tempo lendo. Uma mais inacreditável que a outra. Se inventadas ou não, pouco importa. O efeito delas em mim foi perturbador, sobretudo, por me imaginar na pele daquelas mulheres. Algo simplesmente impossível. Li tendo a sensação de estar sendo visto por elas, por seus olhos penetrantes. Li olhando nos olhos das mulheres que escreveram aquelas histórias impactantes. Naquele instante senti no corpo, mais do que compreendi, a força da narrativa.

Precisei de um tempo de silêncio. Fui ao café do próprio museu. Sentei e pedi uma água sem gás com um pouco de limão espremido. Fiquei por ali. Achei que não conseguiria ver mais nada. Decidi, então, ir até a livraria cultura do Conjunto Nacional. Dar um passeio por entre os livros. Espairecer um pouco. Antes, tirei da mochila o livro do Carrascoza e li mais alguns capítulos. Eles são todos curtos. Ali no café, inundado pelas águas e narrativas propiciadas por Yoko Ono, só pude ler algumas poucas páginas antes de sair caminhando pela avenida Faria Lima até o Largo do Batata para pegar o metrô até a avenida Paulista. E novamente me encharquei da chuva persistente que caia. Levei um pouco dela comigo.

No Conjunto Nacional me senti exausto. Fui até a sala de cinema do espaço e descobri que iria começar, em meia hora, o filme "Eu, o negro", exibido gratuitamente dentro do Festival "É tudo verdade" que estava acontecendo em vários espaços culturais da cidade. Essa ida ao cinema não estava prevista no meu "roteiro", mas me pareceu necessária e oportuna. À espera do início da projeção li um pouco mais do romance que carregava na mochila. O filme era de 1958, dirigido pelo francês Jean Rouch. Incrivelmente atual, tanto com relação à temática como aos modos de filmar. Até aquele momento não sabia da existência do documentarista. O filme era 
sobre a migração de jovens negros do Níger para a Costa do Marfim em busca de melhores condições de trabalho. Pouco ouvimos falar das migrações que acontecem no interior do continente africano. O mais inusitado é que as personagens foram convidadas pelo diretor a encenar seus cotidianos como se fossem astros de cinema. Elas inclusive pareciam dublar as próprias cenas. As tomadas curtas, em uma linguagem aproximada ao que hoje nos acostumamos a ver nos filmes cinematográficos em seus curtíssimos frames, acredito terem sido muito inovadoras para a época, bem como, a ficção entremeada à narrativa documental. Foi uma descoberta incrível.

Sai do cinema e a cidade já estava entregue ao começo da noite. Ainda havia tempo para ver as fotografias de Henri Cartier-Bresson expostas em uma galeria do SESI. E lá fui eu, caminhando lentamente pela agitada avenida. Não consegui aproveitar muito delas, pois meu corpo já não acompanhava meus pensamentos. Vocês podem notar que conforme foi passando o dia, menos anotações fui fazendo, menos pude escrever com os acontecimentos vividos. Era hora de voltar. Em frente a uma das mais famosas imagens do fotógrafo - intitulada "Atrás da Gare Saint-Lazare”, Paris, 1932 - descobri que meu dia já havia se encerrado. O fim chega, comumente, antes de algo terminar. Algo semelhante aconteceu, quem sabe, com essa carta. Acredito que seu fim esteja em algum momento anterior. Vocês saberiam me dizer qual seria?

Beijos e abraços,

Leandro Belinaso Guimarães

Ilha de Santa Catarina, 30 de abril de 2017

(manhã de domingo)

\section{Referências}

AUGÉ, Marc. Efeito pedalada. Piseagrama, n. 7. Belo Horizonte, 2015.

CARRASCOZA, João Anzanello. Trilogia do adeus. São Paulo: Alfaguara, 2017.

HEMPKEMEYER, Sheila. Pedalar: uma experiência educativa sobre duas rodas na cidade. 2016.

Dissertação (Educação) - Universidade Federal de Santa Catarina, Santa Catarina, 2016.

LOPONTE, Luciana. Artes visuais como plataforma para pensar e viver: outros espaços para a docência. In: CHAVES, Silvia; BRITO, Maria (Org.). Formação, ciência e arte: autobiografia, arte e ciência na docência. São Paulo: Livraria da Física, 2016.

SALOMÃO, Waly. Poesia total. São Paulo: Companhia das Letras, 2014.

Quaestio, Sorocaba, SP, v. 19, n. 3, p. 579-590, dez. 2017. 
SILVA, Breno; GANZ, Louise. Lotes vagos: ocupações experimentais. Belo Horizonte: Instituto Cidades Criativas, 2009.

Leandro Belinaso Guimarães - Universidade Federal de Santa Catarina. Florianópolis | SC | Brasil. Contato: lebelinaso@gmail.com 